\title{
Article \\ A Survey on Stretching Practices in Women and Men from Various Sports or Physical Activity Programs
}

\author{
Nicolas Babault*(D), Gaelyann Rodot, Marrain Champelovier and Carole Cometti \\ Center for Performance Expertise, CAPS, U1093 INSERM, University of Bourgogne-Franche-Comté, \\ Faculty of Sport Sciences, 3 allée des Stades Universitaires, BP 27877, 21078 Dijon CEDEX, France; \\ gaelrodot@gmail.com (G.R.); marrain.champelovier@gmail.com (M.C.); carole.cometti@u-bourgogne.fr (C.C.) \\ * Correspondence: nicolas.babault@u-bourgogne.fr; Tel.: +33-380-396-743
}

check for

updates

Citation: Babault, N.; Rodot, G.; Champelovier, M.; Cometti, C. A Survey on Stretching Practices in Women and Men from Various Sports or Physical Activity Programs. Int. J. Environ. Res. Public Health 2021, 18, 3928. https://doi.org/10.3390/ ijerph18083928

Academic Editors: João Martins and João Costa

Received: 1 March 2021

Accepted: 7 April 2021

Published: 8 April 2021

Publisher's Note: MDPI stays neutra with regard to jurisdictional claims in published maps and institutional affiliations.

Copyright: (C) 2021 by the authors. Licensee MDPI, Basel, Switzerland. This article is an open access article distributed under the terms and conditions of the Creative Commons Attribution (CC BY) license (https:// creativecommons.org/licenses/by/ $4.0 /)$

\begin{abstract}
Recommendations for prescribing stretching exercises are regularly updated. It appears that coaches progressively follow the published guidelines, but the real stretching practices of athletes are unknown. The present study aimed to investigate stretching practices in individuals from various sports or physical activity programs. A survey was completed online to determine some general aspects of stretching practices. The survey consisted of 32 multiple-choice or open-ended questions to illustrate the general practices of stretching, experiences and reasons for stretching. In total, 3546 questionnaires were analyzed (47.3\% women and $52.7 \%$ men). Respondents practiced at the national/international level (25.2\%), regional level (29.8\%), or recreationally (44.9\%). Most respondents $(89.3 \%)$ used stretching for recovery $(74.9 \%)$ or gains of flexibility $(57.2 \%)$. Stretching was generally performed after training $(72.4 \%)$. The respondents also indicated they performed stretching as a pre-exercise routine (for warm-up: $49.9 \%$ ). Static stretching was primarily used (88.2\%) but when applied for warm-up reasons, respondents mostly indicated performing dynamic stretching (86.2\%). Only $37.1 \%$ of the respondents indicated being supervised. Finally, some gender and practice level differences were noticed. The present survey revealed that the stretching practices were only partly in agreement with recent evidence-based recommendations. The present survey also pointed out the need to improve the supervision of stretching exercises.
\end{abstract}

Keywords: training; warm-up; injury; performance; recovery; periodization; methodology; health; wellness; gender; competitive level

\section{Introduction}

Stretching is a very popular and extensively documented [1] exercise modality. It is generally used for health, recreation, and performance. For instance, stretching exercises are implemented in various physical activity programs for therapeutic reasons in different diseases such as rheumatoid arthritis [2] or to correct muscle imbalance in elderly individuals [3]. To date, thousands of scientific papers have been published to determine the acute or chronic effects of stretching [4-7] and, depending on the objective, to find the best stretching technique [8]. Briefly, stretching exercises are generally used as pre- and/or post-activity routines to increase joint range of motion, health, muscle performance, to promote recovery after exhaustive exercises, or to reduce activity-related injury risks [9-13].

More specifically, numerous studies revealed that flexibility increased with different efficiency after static, dynamic or proprioceptive neuromuscular facilitation (PNF) stretching techniques [14-19]. Other derivative techniques such as oscillation could also be used for increasing the range of motion without compromising strength [20]. This well-known increased range of motion and concomitant reduced stiffness are often cited to justify the use of stretching as an injury preventive strategy $[10,21]$. Muscles are supposed to have an increased ability to resist to excessive elongations [9]. However, evidence for injury prevention remained equivocal and numerous studies presented unclear conclusions [13,22-24]. Equivocal conclusions were also obtained when considering recovery. While stretching 
has been shown to minimize muscle soreness and reduce damaging effects of different metabolites [25], the effects on strength or power restoration remain unclear [12,26,27].

Stretching exercises demonstrated multiple effects on the neuromuscular system. While chronic stretching could, in some situations, enhance strength $[28,29]$, acute effects on strength or power are still debated [11,30,31]. Starting from the late 1990s, authors have concluded that static stretching induced transient decreases in strength [32]. However, numerous stretching parameters have been shown to alter stretching-induced effects on force output. Stretching duration [11,33,34], stretching modality [35], or inclusion inside dynamic activities $[36,37]$ are key factors shown to significantly impact acute strength alterations.

Based on evolving evidence, regularly updated recommendations are made. For example, the Canadian Society for Exercise Physiology recommended using dynamic stretching as a pre-exercise routine instead of static stretching and that static stretching longer than $60 \mathrm{~s}$ per individual muscle group should be avoided [10]. Unfortunately, it appeared that coaches or athletic trainers from various sports did not follow these recommendations or recent research findings [38,39]. Nevertheless, this general trend seemed to be reversed. In a recent study, the authors concluded that most soccer coaches from the NCAA adhered to the most recent recommendations [40]. Beside the prescriptions of coaches have been previously explored, to the best of our knowledge, the stretching practices of athletes have not been directly investigated. Athletes' practices have indirectly been reported by coaches [39]. Because sport or physical activities are not always supervised by any type of sport or health professionals, identifying stretching practices are of paramount importance to give adequate practical guidelines for performance as well as for health benefits. Therefore, the purpose of the present study was to investigate the general stretching practices of individuals from various sports or physical activity programs. We also attempted to determine whether stretching practices were performed empirically or under some professionals supervision or at least recommendations. We hypothesized that most individuals have a general practice far from scientific conclusions and that most individuals are not assisted during their practice. Finally, because stretching practices could be influenced by several factors, special attention was given to determine some potential differences depending on the practice level or gender.

\section{Materials and Methods}

\subsection{Subjects}

The questionnaire was electronically distributed, mostly in France, by using different social and personal networks (e.g., universities, sport sciences faculties, sport federations, coaches, physiotherapists, and widely used international social networks). A message was sent with a hyperlink to the online survey. The survey first described key information about the study, its purpose, as well as information related to the research team associated with an e-mail contact. The main criterion for responding the present survey was also defined: being active and regularly practicing sport or physical activities (at least once a week) for competition, recreation, or health. Participants were then clearly informed their written consent was obtained by responding to the survey. The questionnaire and all additional information were in French. The procedure was approved by the local ethical review board (AR2020-08) and was performed in accordance with the Declaration of Helsinki.

\subsection{Procedure}

The online survey consisted of a maximal of 32 multiple-choice or open-ended questions. For some questions, multiple responses were allowed. Depending on answers, the participants had to respond different questions to obtain additional details if necessary. The questionnaire was online for two months (from the very beginning of March to beginning of May 2020). All questions and answers are presented in Supplementary Table S1.

The specifically designed questionnaire was based on extensive discussions, suggestions, and feedback between the research team, coaches, and athletes. Coaches and athletes 
( 20) were questioned during the questionnaire conception. They were from various sports (individuals or team sports), levels (from beginners to elite athletes), and all obtained high coaching education diploma (for coaches). Also, coaches and athletes from various sports (10) helped the research team to verify the clarity and flow of the survey. They were instructed to respond to the survey according to their real practice and, at the end of the survey, to comment all possible unclear questions or response possibilities. Finally, the content of the final version of the questionnaire was validated by calculating the content validity index (CVI). Eight experts (including coaches and scientists) were requested to rate the relevance of the different items questioned. The content of the present survey was validated with an average scale-CVI greater than 0.91 .

The questions of the final version of the present survey covered five main themes: (i) characteristics of the participants such as age, sex, sport, training volume, level, and subjective flexibility evaluation (questions 1-6); (ii) general practices of stretching including the main reasons, the body parts, the frequency and duration (questions 7-16); (iii) stretching education or supervision (questions 17-23); (iv) stretching modalities and their potential effects for performance, recovery, wellness and flexibility (questions 24-29) and (v) injury history and potential effects of stretching on injury prevention (questions 30-32). Additional free-text boxes were used for participants who wanted to provide additional comments. These comments were registered. We arbitrary decided to take into consideration these additional comments when more than 10 participants raised the same comment. Also, care was taken to avoid potential missing responses by using mandatory answers while completing the questionnaire.

\subsection{Data and Statistical Analysis}

Data were first reviewed and incomplete responses or from individuals without any actual sport practice were excluded from analyses. We analyzed the distribution of the response frequencies. Descriptive statistics are reported in the form of percentages and counts. Depending on sex or total sample, percentages were calculated as a function of total respondents for the corresponding question. Subgroup analyses were carried out to compare responses according to sex (women vs. men) and to the practice level (national/international vs. regional vs. recreational). The frequency rates were compared using two-tailed Chi-square tests with the significance level set at $p<0.05$. The Cramer's V scores illustrating the effect sizes were also calculated from the chi-square and presented in Supplementary Table S2. In case of significant Chi-square, pairwise comparisons were achieved by calculating Z-scores. Statistics were performed using JASP (Ver 0.13, JASP Team (2020), University of Amsterdam, Amsterdam, The Netherlands) and SPSS (Ver 27, IBM-SPSS Inc., Armonk, NY, USA).

\section{Results}

\subsection{Characteristics of Participants}

A total of 3572 responses were obtained. Twenty-six responses were excluded from the analyses because the respondents did not meet the main inclusion criterion (training at least once a week). A total of 3546 questionnaires were therefore analyzed. Statistical analyses indicated significant different frequency distributions between gender and practice level for age, sport, level, training volume, and subjective flexibility $(p<0.001)$ (Table 1$)$. Briefly, women were younger, mostly recreative with shorter training volume per week $(<6 \mathrm{~h})$ and with higher flexibility than men. The frequency was greater for women than men for Dance/Gymnastics, Equestrian/golf, Fitness and Swimming while it was greater for men for Cycling/trail/triathlon, Racket sports, and Team Sports. Finally, recreative individuals mostly performed fitness and strength of long-duration activities. 
Table 1. Participants' characteristics.

\begin{tabular}{|c|c|c|c|c|c|}
\hline \multirow[b]{2}{*}{ Descriptor } & \multicolumn{2}{|c|}{ Gender $\$ \$ \$$} & \multicolumn{3}{|c|}{ Practice level $^{£ f f}$} \\
\hline & Women & Men & Nat./Internat. & Regional & Recreative \\
\hline \multicolumn{6}{|c|}{ What is your gender? } \\
\hline Women ${ }^{b, c, d}$ & $47.3 \%$ (1677) & - & $41.3 \%(371)$ & $34.4 \%(364)$ & $59.2 \%(942)$ \\
\hline Men ${ }^{b, c, d}$ & - & $\begin{array}{l}52.7 \% \\
(1869)\end{array}$ & $58.7 \%(527)$ & $65.6 \%(693)$ & $40.8 \%(549)$ \\
\hline \multicolumn{6}{|c|}{ What is your age? } \\
\hline$<20$ years ${ }^{a, b, c, d}$ & $32.8 \%(550)$ & $24.9 \%(465)$ & $37.3 \%(335)$ & $30.4 \%(322)$ & $22.5 \%(358)$ \\
\hline 20-29 years & $51.2 \%(859)$ & $48.1 \%(899)$ & $50.3 \%(452)$ & $47.5 \%(502)$ & $50.5 \%(804)$ \\
\hline $30-39$ years ${ }^{a, c}$ & $6.4 \%(107)$ & $9.8 \%(183)$ & $6.8 \%(61)$ & $9.5 \%(101)$ & $8.0 \%(128)$ \\
\hline $40-49$ years $^{\mathrm{a}, \mathrm{b}, \mathrm{c}, \mathrm{d}}$ & $5.1 \%(85)$ & $10.0 \%(187)$ & $4.0 \%(36)$ & $7.6 \%(80)$ & $9.8 \%(80)$ \\
\hline 50-59 years ${ }^{a, b, c, d}$ & $3.9 \%(65)$ & $5.3 \%(99)$ & $1.4 \%(13)$ & $3.9 \%(42)$ & $6.8 \%(42)$ \\
\hline$>60$ years $\mathrm{a}, \mathrm{b}, \mathrm{c}, \mathrm{d}$ & $0.6 \%(11)$ & $1.9 \%(36)$ & $0.1 \%(1)$ & $0.9 \%(10)$ & $2.2 \%(10)$ \\
\hline \multicolumn{6}{|c|}{ What is the main sport you are actually doing? } \\
\hline Team Sports $a, b, c, d$ & $18.3 \%(307)$ & $40.8 \%(762)$ & $43.5 \%(391)$ & $55.0 \%(581)$ & $6.1 \%(97)$ \\
\hline Fitness ${ }^{a, b, c, d}$ & $21.3 \%(357)$ & $3.1 \%(58)$ & $0.4 \%(4)$ & $0.8 \%(8)$ & $25.3 \%(403)$ \\
\hline Strength/crossfit ${ }^{a, c, d}$ & $8.6 \%(144)$ & $11.3 \%(211)$ & $1.8 \%(16)$ & $2.2 \%(23)$ & $19.9 \%(316)$ \\
\hline Track \& Field & $9.2 \%(154)$ & $8.7 \%(162)$ & $9.8 \%(88)$ & $9.6 \%(101)$ & $8.0 \%(127)$ \\
\hline Cycling/Trail/Triathlon a,b,c,d & $7.1 \%(120)$ & $10.5 \%(196)$ & $7.1 \%(64)$ & $5.8 \%(61)$ & $12.0 \%(191)$ \\
\hline Racket Sport $\mathrm{a}, \mathrm{b}, \mathrm{c}, \mathrm{d}$ & $5.3 \%(88)$ & $11.0 \%(206)$ & $6.7 \%(60)$ & $15.1 \%(160)$ & $4.7 \%(74)$ \\
\hline Dance/Gymnastics a,b,d & $14.5 \%(243)$ & $1.5 \%(29)$ & $10.4 \%(93)$ & $3.0 \%(32)$ & $9.2 \%(147)$ \\
\hline Martial Arts $b, c, d$ & $4.8 \%(80)$ & $5.2 \%(98)$ & $8.7 \%(78)$ & $2.6 \%(27)$ & $4.6 \%(73)$ \\
\hline Swimming & $3.3 \%(56)$ & $2.3 \%(44)$ & $2.8 \%(25)$ & $2.4 \%(25)$ & $3.1 \%(50)$ \\
\hline Mountain/water sports b,d & $2.6 \%(44)$ & $3.0 \%(57)$ & $4.5 \%(40)$ & $0.9 \%(9)$ & $3.3 \%(52)$ \\
\hline Equestrian/Golf ${ }^{\text {a }}$ & $3.5 \%(59)$ & $0.6 \%(11)$ & $2.2 \%(20)$ & $2.1 \%(22)$ & $1.8 \%(28)$ \\
\hline Others $\mathrm{b}, \mathrm{d}$ & $1.5 \%(25)$ & $1.9 \%(35)$ & $2.1 \%(19)$ & $0.8 \%(8)$ & $2.1 \%(33)$ \\
\hline \multicolumn{6}{|c|}{ What is your practice level? } \\
\hline National/international ${ }^{\text {a }}$ & $22.2 \%(371)$ & $28.2 \%(527)$ & - & - & - \\
\hline Regional $^{\text {a }}$ & $21.7 \%(364)$ & $37.1 \%(693)$ & - & - & - \\
\hline Recreative $^{\text {a }}$ & $56.2 \%(942)$ & $34.7 \%(649)$ & - & - & - \\
\hline \multicolumn{6}{|c|}{ What is your training volume? } \\
\hline$<2 \mathrm{~h} /$ week $^{\mathrm{a}, \mathrm{b}, \mathrm{c}, \mathrm{d}}$ & $21.3 \%(357)$ & $14.6 \%(273)$ & $6.1 \%(55)$ & $14.6 \%(154)$ & $26.5 \%(421)$ \\
\hline $3-6 \mathrm{~h} /$ week $^{\mathrm{a}, \mathrm{c}, \mathrm{d}}$ & $44.9 \%(754)$ & $38.6 \%(722)$ & $27.7 \%(249)$ & $42.2 \%(446)$ & $49.1 \%(781)$ \\
\hline 7-10 h/week ${ }^{a, b, c, d}$ & $22.2 \%(373)$ & $26.6 \%(497)$ & $28.6 \%(257)$ & $31.0 \%(328)$ & $17.9 \%(285)$ \\
\hline$>10 \mathrm{~h} /$ week $^{\mathrm{a}, \mathrm{b}, \mathrm{c}, \mathrm{d}}$ & $11.5 \%(193)$ & $20.2 \%(377)$ & $37.5 \%(337)$ & $12.2 \%(129)$ & $6.5 \%(104)$ \\
\hline \multicolumn{6}{|c|}{ What is your subjective flexibility? } \\
\hline Very low ${ }^{\text {a }}$ & $12.2 \%(205)$ & $22.5 \%(421)$ & $13.8 \%(124)$ & $22.1 \%(234)$ & $16.8 \%(268)$ \\
\hline Low $a, b, d$ & $36.9 \%(619)$ & $45.1 \%(843)$ & $39.5 \%(355)$ & $46.5 \%(491)$ & $38.7 \%(616)$ \\
\hline $\operatorname{High}^{\mathrm{a}, \mathrm{b}, \mathrm{d}}$ & $41.1 \%(690)$ & $28.9 \%(540)$ & $37.6 \%(338)$ & $27.4 \%(290)$ & $37.8 \%(602)$ \\
\hline Very high ${ }^{\text {a }}$ & $9.7 \%(163)$ & $3.5 \%(65)$ & $9.0 \%(81)$ & $4.0 \%(42)$ & $6.6 \%(105)$ \\
\hline
\end{tabular}

Values are presented as percentages and number of respondents $(n)$. Significant frequency distribution differences between men and women $\left(\$ \$\right.$ ) or between practice levels $\left({ }^{f f f}\right)$ for all questions $(p<0.001)$. Significant differences using Z-scores for a given item between $\left({ }^{a}\right)$ women and men, $\left({ }^{b}\right)$ nat./internat. and regional, $\left({ }^{c}\right)$ nat./internat. and recreative and $\left({ }^{\mathrm{d}}\right)$ regional and recreative $(p<0.05)$. Nat./Internat.: national/international level.

\subsection{General Stretching Practice}

Most respondents indicated they felt the necessity to stretch and conducted stretching during the last two years (Figure 1). Frequency distribution revealed more "yes" responses for women than men $(p<0.001)$ but no difference was observed for the different practice levels $(p=0.139)$. Briefly, individuals mostly indicated it was a necessity because of muscle pain $(59.6 \%)$, muscle stiffness $(59.0 \%)$, or simply for wellness $(60.0 \%)$. The majority indicated it was a necessity after training or competition (77.9\%) or after a series of training or competition (32.6\%). No difference in distribution was obtained between women and men for these two last questions ( $p=0.092$ and $p=0.074$, respectively). In contrast, significant frequency distributions differences were obtained depending on the practice level $(p<0.001)$. 

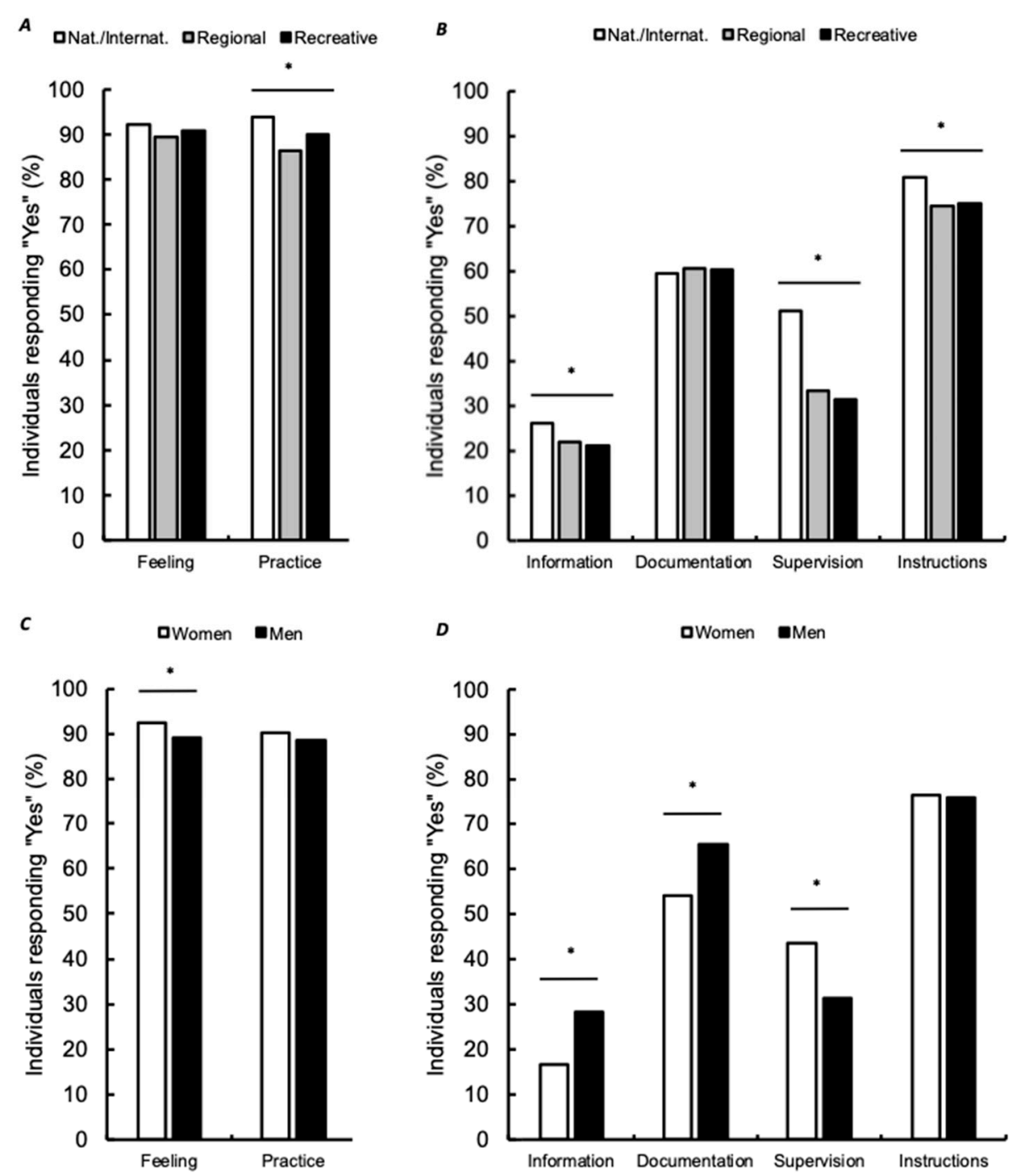

Figure 1. Percentages of "yes" to different questions. Feeling: Do you already feel the necessity to do stretching exercises? Practice: Did you conduct stretching exercises during the last two years? Information: Did you receive any information about stretching during your education? Documentation: Did you look at some documentation to help you understand and perform stretching? Supervision: Are stretching exercises supervised? Instructions: Do you have instruction to perform stretching? Feeling and practice are shown as a function of practice level (A) and gender (C). Information, documentation, supervision and instructions are shown as a function of practice level (B) and gender (D). Percentages of "yes" are shown and expressed as a function of the total number of respondents for a given practice level or gender. Significant frequency distribution differences obtained from chi-square and Z-scores between women and men or between nat./internat. and both regional and recreative individuals are shown $\left({ }^{*} p<0.001\right)$. Nat./Internat.: national/international level.

Almost similarly, most respondents performed stretching within the last two years (Figure 1). The responses were not different between women and men $(p=0.108)$ but individuals in a regional level performed less stretching than those recreational and performing at a national/international level $(p<0.001)$. Participants who did not conduct stretching indicated it was because of a lack of motivation (26\%), time (22\%), knowledge (why and how to do, $20 \%$ and $13.7 \%$, respectively), lack of supervision $(10.3 \%)$, or poor efficiency $(6.4 \%)$. Individuals performing stretching mostly responded it was for recovery, to gain flexibility, for injury prevention and performance (Table 2). As compared to men $(p<0.001)$, women mostly indicated it was for recovery. Comparing practice level revealed, recreational individuals mostly conducted stretching exercises for wellness while competition 
athletes mostly looked for injury prevention and warm-up effects $(p<0.001)$. Stretching was mostly performed after training, then in dedicated sessions or before training. Women distribution was greater for the answer "after training" than men $(p=0.006)$. Recreative individuals mostly performed stretching after training/competition $(p<0.001)$. Stretching frequency was mostly " 1 to 5 times a week" and "during every training". No difference was obtained between women and men $(p=0.121)$. National/international individuals mostly practiced stretching every day than the others $(p<0.001)$. Stretching sessions were mostly shorter than 15 min without any difference between women and men $(p=0.414)$ but with shorter stretching sessions for competitive athletes as compared to recreational individuals $(p<0.001)$. Finally, stretching was mostly performed over the whole body with significant differences between women and men $(p<0.001)$.

Table 2. General stretching practices.

\begin{tabular}{|c|c|c|c|c|c|}
\hline \multirow[b]{2}{*}{ Descriptor } & \multicolumn{2}{|c|}{ Gender $\$ \$ \$$} & \multicolumn{3}{|c|}{ Practice level ${ }^{£ f f}$} \\
\hline & Women & Men & Nat./Internat. & Regional & Recreative \\
\hline \multicolumn{6}{|c|}{ For what reason? * } \\
\hline Wellness ${ }^{a, b, c, d}$ & $56.2 \%(850)$ & $43.4 \%(714)$ & $14.3 \%(386)$ & $14.1 \%(393)$ & $18.7 \%(789)$ \\
\hline Warm-up ${ }^{\mathrm{b}, \mathrm{c}, \mathrm{d}}$ & $50.3 \%(761)$ & $49.6 \%(821)$ & $17.2 \%(463)$ & $17.7 \%(494)$ & $14.8 \%(626)$ \\
\hline Injury prevention ${ }^{a, c, d}$ & $51.4 \%(778)$ & $58.8 \%(973)$ & $19.3 \%(521)$ & $20.3 \%(567)$ & $15.5 \%(654)$ \\
\hline Gain flexibility $b, c, d$ & $59.1 \%(894)$ & $55.5 \%(919)$ & $19.3 \%(520)$ & $17.3 \%(484)$ & $19.2 \%(810)$ \\
\hline Recovery ${ }^{a, b, c}$ & $81.0 \%(1226)$ & $69.3 \%(1147)$ & $24.1 \%(650)$ & $24.4 \%(682)$ & $24.6 \%(1040)$ \\
\hline Health & $19.1 \%(289)$ & $20.3 \%(336)$ & $5.8 \%(157)$ & $6.1 \%(171)$ & $7.1 \%(302)$ \\
\hline \multicolumn{6}{|c|}{ When?* } \\
\hline Before training $b, c, d$ & $44.7 \%(676)$ & $45.3 \%(750)$ & $19.6 \%(440)$ & $19.3 \%(434)$ & $19.7 \%(550)$ \\
\hline During training ${ }^{\mathrm{c}, \mathrm{d}}$ & $17.4 \%(263)$ & $19.4 \%(322)$ & $8.6 \%(193)$ & $8.6 \%(193)$ & $7.3 \%(203)$ \\
\hline After training/competition ${ }^{a, b, c}$ & $76.1 \%(1152)$ & $68.9 \%(1141)$ & $28.6 \%(641)$ & $30.3 \%(681)$ & $34.7 \%(970)$ \\
\hline $\begin{array}{l}\text { After series of } \\
\text { training/competition } \mathrm{b}, \mathrm{c}, \mathrm{d}\end{array}$ & $30.9 \%(468)$ & $32.9 \%(544)$ & $18.8 \%(422)$ & $17.3 \%(388)$ & $11.9 \%(334)$ \\
\hline Dedicated sessions $b, c, d$ & $49.2 \%(745)$ & $51.0 \%(845)$ & $24.4 \%(547)$ & $24.4 \%(549)$ & $26.3 \%(736)$ \\
\hline \multicolumn{6}{|c|}{ With what frequency? } \\
\hline Every day $b, c, d$ & $10.3 \%(156)$ & $9.0 \%(150)$ & $13.6 \%(115)$ & $6.4 \%(61)$ & $9.4 \%(130)$ \\
\hline During every training ${ }^{c}$ & $28.6 \%(432)$ & $24.5 \%(407)$ & $21.8 \%(184)$ & $26.3 \%(250)$ & $29.4 \%(405)$ \\
\hline 1 to 5 times a week & $43.4 \%(655)$ & $43.5 \%(722)$ & $43.0 \%(363)$ & $42.9 \%(408)$ & $44.1 \%(607)$ \\
\hline 1 to 2 times per month ${ }^{c, d}$ & $13.5 \%(204)$ & $17.4 \%(289)$ & $17.2 \%(145)$ & $18.3 \%(174)$ & $12.6 \%(174)$ \\
\hline 1 to 6 times per year $d$ & $4.2 \%(63)$ & $5.6 \%(93)$ & $4.3 \%(36)$ & $6.1 \%(58)$ & $4.4 \%(61)$ \\
\hline \multicolumn{6}{|c|}{ What is the average duration of stretching exercises (total)? } \\
\hline$<15 \min ^{c, d}$ & $41.2 \%(623)$ & $40.6 \%(712)$ & $47.8 \%(403)$ & $54.7 \%(520)$ & $29.9 \%(412)$ \\
\hline Between 15 and $30 \mathrm{~min}$ & $27.3 \%(412)$ & $27.4 \%(480)$ & $24.9 \%(210)$ & $28.1 \%(267)$ & $30.1 \%(415)$ \\
\hline Between 30 and $60 \min { }^{b, c, d}$ & $29.5 \%(446)$ & $30.7 \%(539)$ & $26.1 \%(220)$ & $16.1 \%(153)$ & $37.6 \%(518)$ \\
\hline$>60 \mathrm{~min}$ & $2.0 \%(30)$ & $1.3 \%(23)$ & $1.2 \%(10)$ & $1.2 \%(11)$ & $2.3 \%(32)$ \\
\hline \multicolumn{6}{|c|}{ What part of your body? } \\
\hline Lower $^{a}$ & $19.6 \%(277)$ & $29.8 \%(494)$ & $25.8 \%(217)$ & $18.9 \%(294)$ & $30.1 \%(260)$ \\
\hline Upper $^{\mathrm{a}}$ & $0.8 \%(12)$ & $1.8 \%(29)$ & $1.5 \%(13)$ & $1.2 \%(44)$ & $1.1 \%(17)$ \\
\hline Both ${ }^{a}$ & $79.5 \%(1124)$ & $68.4 \%(1132)$ & $72.7 \%(612)$ & $79.8 \%(646)$ & $67.9 \%(1098)$ \\
\hline
\end{tabular}

Values are presented as percentages and number of respondents $(n)$. Questions with potential multiple responses are shown $(*)$. $\$ \$$ significant frequency distribution differences between women and men except for stretching frequency and duration $(p<0.001)$. $£ £ £$ significant frequency distribution differences between practice levels for all questions $(p<0.001)$. Significant differences using Z-scores for a given item between $\left({ }^{\mathrm{a}}\right)$ women and men, $\left({ }^{b}\right)$ nat. /internat. and regional, $\left({ }^{c}\right)$ nat./internat. and recreative and $\left({ }^{\mathrm{d}}\right)$ regional and recreative $(p<0.05)$. Nat./Internat.: national/international level.

\subsection{Education and Supervision}

Most respondents indicated not receiving any information during their education (Figure 1) but that they often looked for information $(\sim 60 \%)$ while reading books $(45.0 \%)$, discussing with others $(47.0 \%)$, or surfing the internet $(34.5 \%)$. Two third of the individuals are not supervised during stretching. Women indicated they were more supervised than men $(p<0.001)$. Similarly, national/international levels individuals indicated being more supervised than the other levels $(p<0.001)$. Stretching was mostly supervised by coaches $(95.3 \%)$ then by health professionals (34.5\%) and other athletes (24.7\%). Responses were 
similar between women and men $(p=0.134)$ but coaches mostly supervised stretching sessions in national/international individuals as compared to the other practice levels $(p<0.036)$. In contrast, most individuals responded receiving instructions $(76.2 \%)$. No difference was obtained between women and men $(p=0.641)$ but national/international individuals obtained much more instructions than the others $(p=0.002)$. Instructions were mostly given by coaches $(92.8 \%)$ or health professionals $(61.7 \%)$. Instructions were also given during individuals' education $(25.7 \%)$ or by other athletes $(16.9 \%)$. No difference was obtained between gender and practice level ( $p=0.086$ and $p=0.099$, respectively).

\subsection{Stretching Modalities}

In our study, $61.7 \%$ of the participants indicated knowing different stretching modalities. The distribution of "yes" was greater in men than women $(68.3 \%$ and $54.5 \%$, respectively, $p<0.001)$ and greater in national/international than recreative and regional individuals $(70.0 \%, 64.9 \%$ and $54.9 \%$, respectively, $p<0.001)$. For individuals responding "yes", additional questions were provided. Individuals had to indicate whether they generally used these techniques (Figure 2) and to specify the expected effect (performance, recovery, wellness or flexibility; Figure 3).

A

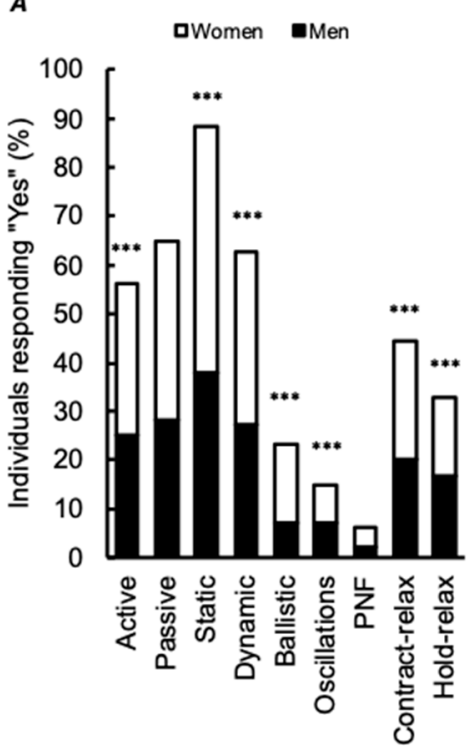

B

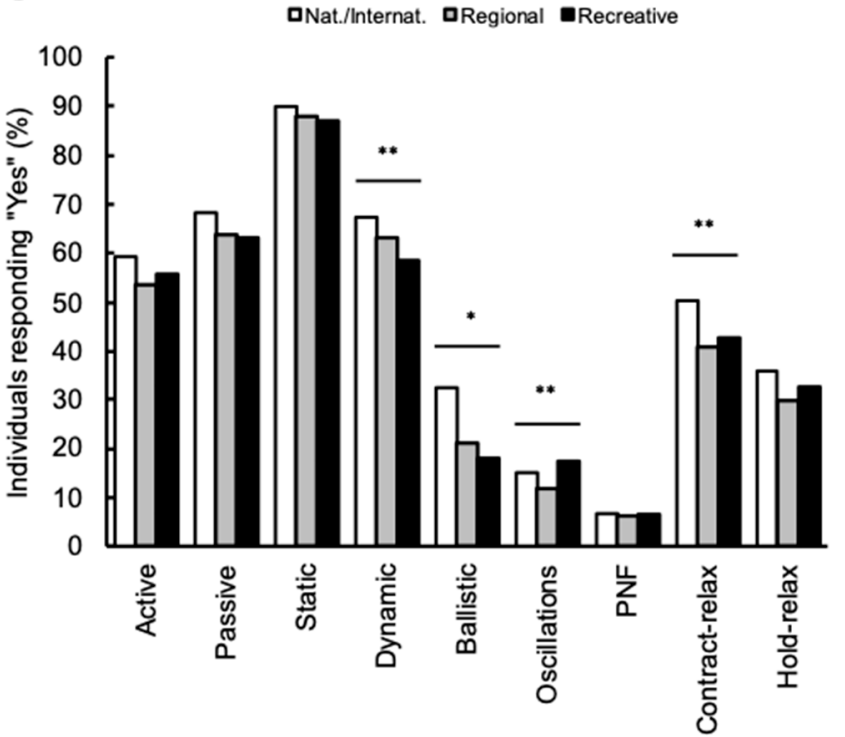

Figure 2. (A) Stretching modalities generally used as a function of gender. Percentages of "yes" are shown and expressed as a function of the total number of respondents. Repartition between women (black part of histogram) and men (white part of histogram) are also shown. (B) Stretching modalities generally used as a function of practice level. Percentages of "yes" are shown and expressed as a function of the total number of respondents for a given practice level. Significant frequency distribution differences between gender or practice level are shown $\left({ }^{*}: p<0.05,{ }^{* *} p<0.01\right.$ and $\left.{ }^{* * *} p<0.001\right)$. For oscillation, nat. /internat. individuals were not different from recreative (Z-score results). For contractrelax, no difference was obtained between regional and recreative individuals (Z-score results). PNF: proprioceptive neuromuscular facilitation. Nat./Internat.: national/international level. 
口Nat./Internat. QRegional $\mathbf{\square}$ Recreative

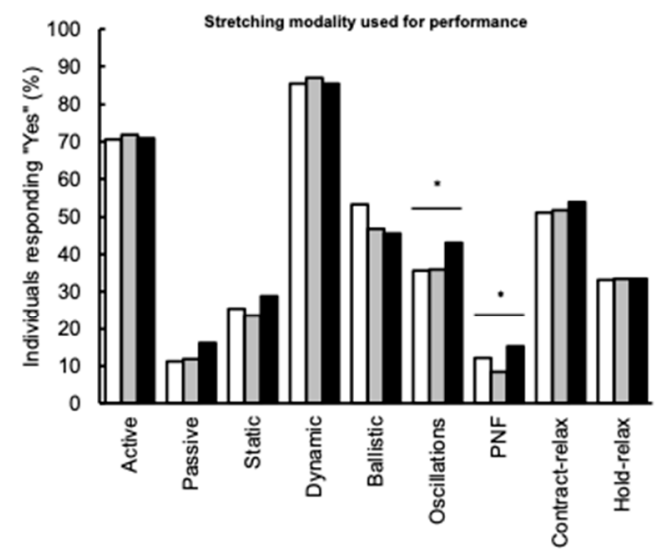

c

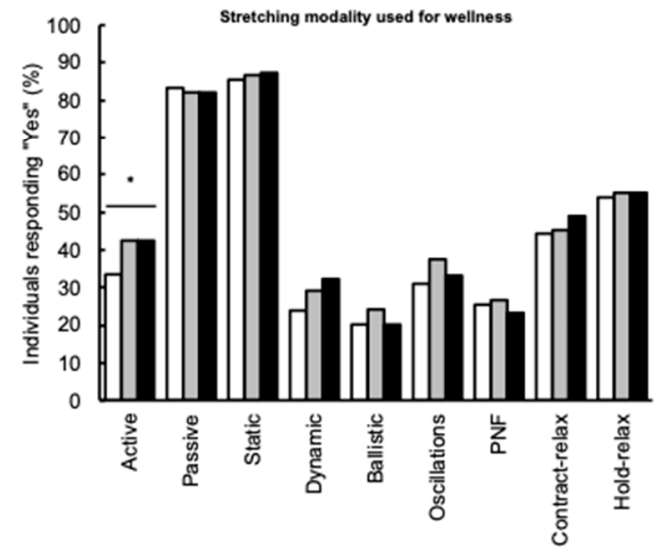

B

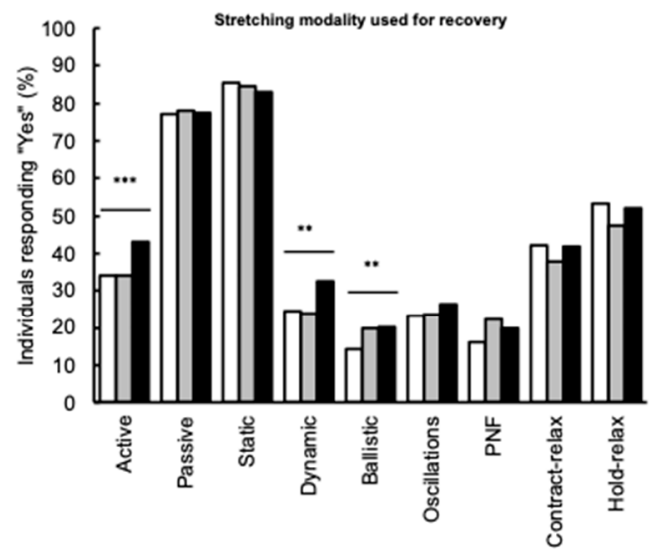

D

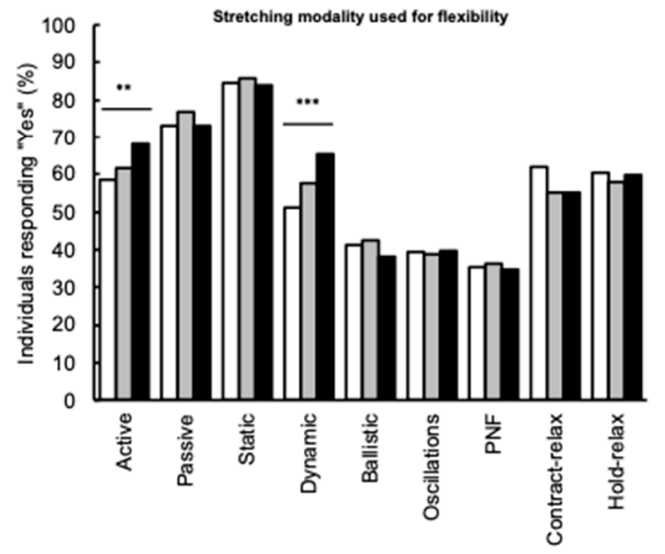

Figure 3. Stretching modalities used for performance enhancement (A), for recovery (B), for wellness (C), and for flexibility (D). Percentages of "yes" are shown and expressed as a function of the total number of respondents for a given practice level. Significant frequency distribution differences between all practice level are shown $\left(^{*}: p<0.05,{ }^{* *} p<0.01\right.$ and $\left.{ }^{* *} p<0.001\right)$. For panel A, no difference was observed between nat./internat. and regional for oscillation and between nat./internat. and recreative for PNF (Z-score results). For panel B, nat./internat. were not different than regional for active and dynamic stretching and no difference was obtained between regional and recreative individuals for ballistic (Z-score results). For panel C, no difference was obtained between regional and recreative individuals (Z-score results). PNF: proprioceptive neuromuscular facilitation. Nat./Internat.: national/international level.

\subsection{Injury}

In our study, $45.1 \%$ of the respondents reported getting injured during the last 12 months (Table 3$)$. Injury was more present in men than women $(p<0.001)$ and less in recreative individuals $(p<0.001)$. In case of injury, $47.4 \%$ responded that performing more stretching would not have help them avoid being injured. National/international individuals mostly indicated stretching would not have avoided their injuries $(p=0.004)$. In case of no injury, $84.9 \%$ responded stretching was efficient to avoid injury or was likely efficient to avoid injury. Significant differences were observed between women and men $(p=0.003)$ while no difference was obtained between practice level $(p=0.172)$. 
Table 3. Stretching and injury.

\begin{tabular}{|c|c|c|c|c|c|}
\hline \multirow[b]{2}{*}{ Descriptor } & \multicolumn{2}{|c|}{ Gender \$\$ } & \multicolumn{3}{|c|}{ Practice level $^{£ £}$} \\
\hline & Women & Men & Nat./Internat. & Regional & Recreative \\
\hline \multicolumn{6}{|c|}{ Did you get injured during the last 12 months? } \\
\hline Yes ${ }^{a, c, d}$ & $40.7 \%(683)$ & $49.0 \%(915)$ & $57.2 \%(514)$ & $54.7 \%(579)$ & $31.7 \%(505)$ \\
\hline $\mathrm{No}^{\mathrm{a}, \mathrm{c}, \mathrm{d}}$ & $59.3 \%(994)$ & $51.0 \%(954)$ & $42.7 \%(384)$ & $45.2 \%(478)$ & $68.2 \%(1086)$ \\
\hline \multicolumn{6}{|c|}{ Do you think stretching more could have avoided being injured? (in case of injuries) } \\
\hline Yes ${ }^{a, b, c, d}$ & $26.2 \%(178)$ & $36.0 \%(329)$ & $26.8 \%(138)$ & $34.5 \%(198)$ & $33.9 \%(171)$ \\
\hline No ${ }^{b, c, d}$ & $51.0 \%(346)$ & $44.8 \%(409)$ & $52.9 \%(272)$ & $46.8 \%(269)$ & $42.4 \%(214)$ \\
\hline No opinion ${ }^{c, d}$ & $22.8 \%(155)$ & $19.2 \%(175)$ & $20.2 \%(104)$ & $18.6 \%(107)$ & $23.6 \%(119)$ \\
\hline \multicolumn{6}{|c|}{ Do you think stretching contribute to the absence of injury? (if no injury) } \\
\hline Yes $^{\mathrm{a}}$ & $45.6 \%(452)$ & $41.9 \%(398)$ & $47.6 \%(183)$ & $42.7 \%(204)$ & $42.8 \%(463)$ \\
\hline $\mathrm{No}^{\mathrm{a}}$ & $12.4 \%(123)$ & $18.0 \%(171)$ & $14.5 \%(56)$ & $17.6 \%(84)$ & $14.2 \%(154)$ \\
\hline May be ${ }^{a}$ & $42.0 \%(416)$ & $40.2 \%(382)$ & $37.7 \%(145)$ & $39.6 \%$ (189) & $42.9 \%(464)$ \\
\hline
\end{tabular}

Values are presented as percentages and number of respondents $(n) . \$ \$$ significant frequency distribution differences between men and women for all questions $(p<0.01) .{ }^{£ £}$ significant frequency distribution differences between practice level except for the last question $(p<0.01)$. Significant differences using Z-scores for a given item between $\left({ }^{a}\right)$ women and men, $\left({ }^{b}\right)$ nat./internat. and regional, $\left({ }^{c}\right)$ nat./internat. and recreative and $\left({ }^{\mathrm{d}}\right)$ regional and recreative $(p<0.05)$. Nat./Internat.: national/international level.

\section{Discussion}

The present study aimed to investigate the stretching general practices of athletes from various sports or physical activity programs. Our results revealed that the large majority of athletes are not supervised during stretching exercises, but most received instructions from their coaches and are looking for information. Most conducted stretches at least once a week with stretching sessions lasting less than $15 \mathrm{~min}$, generally for recovery after training sessions or competitions. Only $61.7 \%$ of the respondents knew the existence of different stretching modalities. From these individuals, and contrarily to our hypothesis, most favored the use of dynamic stretching for performance purposes and preferred static stretching for flexibility, recovery or wellness. These general observations are partly concordant with the literature $[10,31,40]$. Beside these conclusions seemed to reveal that athletes generally followed stretching evidence-based recommendations, one should remember that $38.3 \%$ of the respondents were unable to differentiate stretching modalities or terminologies.

\subsection{Stretching Practices}

The respondents of the present survey mostly felt the necessity to stretch to improve flexibility and wellness. Firstly, it is well known that stretching increased flexibility (i.e., range of motion) and/or decreased stiffness [6,41-43]. Secondly, the assumptions for health and wellness benefits were generally concordant with the literature. For instance, multiple studies have tested the effects of stretching programs implemented in office settings [44-47]. These studies were generally conclusive for significantly improved health-related quality of life. However, the time to gain ratio could be questioned. Indeed, stretching is only a part of general fitness programs that should include other components such as strength or endurance. In a very recent paper, the author suggested to retire flexibility from fitness programs [48] so as to partly save time and emphasize the other components that could have more robust benefits for health.

Individuals also responded feeling the necessity to stretch to reduce muscle pain. This result was congruent with the literature since recent evidences demonstrated the positive effects of stretching on pain sensitivity [49] with potential roles in endogenous pain inhibitory systems [50]. For that reason, $74.9 \%$ of the respondents indicated using stretching for recovery (i.e., performance or muscle soreness) and therefore after single or multiple training sessions. However, no clear evidence demonstrated the positive effects of stretching for recovery. Some authors observed small-to-moderate effects on 
perceived muscle soreness and recovery of muscle function after eccentric exercises [51]. In contrast, numerous studies demonstrated stretching was ineffective to decrease muscle soreness $[12,52,53]$ or prevent cramping [54]. When performed during inter-set recovery periods during resistance training, stretching even negatively impacted neuromuscular performance [55]. From the present results, we concluded that athletes apply stretching for recovery while the effects are not clearly evidenced by the scientific literature.

A similar conclusion is obtained while considering injury prevention. More than half of the respondents indicated performing stretching for injury prevention. Surprisingly, the practices and beliefs were somewhat conflicting. Indeed, only $38.4 \%$ indicated stretching was efficient for injury prevention $(29.7 \%$ did not link stretching and injury and the remaining $31.9 \%$ did not know). Interestingly, the results of the present survey for injury were coherent with the literature. Indeed, while injury prevention was often cited to justify the use of stretching during pre-activity warm-up routines $[5,9,10]$, the effects were generally unclear with only limited beneficial results [13,56-59]. In addition, some authors [58] indicated injury incidences were greater in very stiff or very flexible individuals. This suggested that individuals should regularly conduct stretching programs (as revealed here in most individuals) to gain or, at least, to maintain flexibility. This potential link between flexibility and injury prevention was reflected by the present survey. While more women indicated stretching contributed to the absence of injury as compared to men, women and elite individuals indicated that additional stretching would not have avoided injuries. We could speculate such response could be attributed to the subjective flexibility. Indeed, although the direct link could not be verified, women and elite individuals generally estimated their flexibility as higher than the others. In addition, these individuals stretched slightly more frequently while mostly responding looking for gains of flexibility than men or regional level athletes. Obviously, additional analyses should be conducted to link very detailed stretching programs (e.g., frequency, stretching technique, timing) with the type of injury but also with the sport actually practice, training volume or age.

When performed during warm-up (before training or competition), the reasons for using stretching were performance improvement, range of motion gains, or injury prevention. The question of the effectiveness of stretching for performance is currently widely documented. The literature generally agreed with the fact that short durations stretching exercises could be performed within a comprehensive warm-up procedure $[5,10,37]$ and that dynamic stretching (slow conducted dynamic stretch) is recommended [35]. Obviously, for some sports (such as gymnastics), flexibility is part of the performance determinants and stretching should be included as a pre-exercise routine. Hopefully, the authors previously demonstrated that the potential acute detrimental effects of stretching are lower in individuals with greater flexibility [60]. Taken as a whole, these results were contradictory with our initial hypothesis but were concordant with scientific recommendations since individuals mostly reported stretching using short sessions with predominant dynamic or active stretching modalities [61]. Such encouraging finding is consistent with the general coach practices recently documented [40]. Considering older studies [39,62], it suggests that beliefs are positively evolving towards evidence-based practices.

Finally, half of the respondents indicated they performed stretching in dedicated sessions. Interestingly, these specifically designed stretching sessions might favor flexibility improvements while being focused on this training component. Moreover, it could limit some detrimental effects of stretching (such as recovery or acute force decrements). For instance, when stretching is performed for recovery, authors have suggested that it could even have additional negative impacts leading to delayed onset muscle soreness (i.e., eccentric) $[63,64]$. Also, it might alleviate some detrimental performance effects when long duration stretches are programmed [65]. However, whether stretching should be recommended during dedicated sessions requires further investigations. 


\subsection{Education and Supervision}

From the sample considered, and as previously stated, most respondents performed stretching exercises. Very few individuals received information during their education and about half are looking for information while discussing with athletes, coaches or health professionals. However, from the present survey, we cannot estimate the quality of the information received (whether information is up to date). For instance, information could more frequently be related to personal experiences (history of practices or empirical beliefs of potential benefits or drawbacks) rather than scientific evidences [66,67].

Consistent with our hypothesis, the present results indicated that most individuals are not supervised. However, more women were supervised than men. We can speculate that such gender finding can be attributed to the sport performed. Indeed, $35.8 \%$ of women performed dance/gymnastics or general fitness programs against only $4.6 \%$ of men. These sports are well known to include extensive stretching programs for flexibility improvements $[68,69]$. Obviously, coaches or physical trainers mostly supervised stretching exercises. In addition, national/international athletes were more supervised than regional or recreational individuals. This level dependency was not surprising since performing elite sport imposed more coaching professionalism with an exhaustive view of all training components. However, despite this positive information, only $50 \%$ of national/international athletes were supervised during stretching sessions. According to previous studies, supervision did not warrant appropriate practices. Authors have previously acknowledged that coaches could be hesitant to change their habits (for example while suppressing static stretching from pre-activity routines) [39,62]. Moreover, adequate supervision of stretching exercises (technique, volume, intensity) may be arduous with large groups of athletes [39].

Although $62.9 \%$ of the individuals were not supervised, a large proportion $(76.2 \%)$ received instructions from coaches, physical trainers or health professionals. As for supervision, a practice level dependency was observed with more national/international athletes receiving instructions. This result was apparently encouraging for better and adequate stretching interventions. However, even with instructions, the predominant absence of supervision did not guarantee individuals would understand or follow the general recommendations or use appropriate exercises and correct techniques or positioning [70-72]. Supervision should be developed since it is well known to increase training efficiency [73,74].

Most individuals acknowledged the existence of different stretching modalities. The preferred and generally used stretching technique was static followed by dynamic stretching. In the present survey, general PNF techniques was intentionally divided into PNF, contract-relax (concentric contraction preceding a stretch) and hold-relax (isometric contraction preceding a stretch). This apparent dupery revealed that respondents did not know the term PNF whilst they seemed to practice the techniques. Previous studies demonstrated different efficiency between stretching techniques [14-19]. However, other studies failed to demonstrate any gold method to gain flexibility in sport or for rehabilitation $[75,76]$. Considering the general lack of supervision, we could recommend individuals to use the simplest stretching techniques or the technique they usually practice avoiding inappropriate intensity and positioning.

\subsection{Study Limitations}

Some limitations should be acknowledged. The data were collected using a selfreported survey. It could include potential bias related to subjective aspects, terminology understandings and generalization of the practices. Because this survey aimed to have an overview of a general stretching practices, the specific and very detailed stretching processes were not determined here. Detailed stretching exercises, duration, and intensity would have been of interest. Moreover, although the present survey was completed by 3546 individuals, more respondents would have increased the strength of our conclusions. Increasing the number of respondents would have permitted to discriminate practices 
between age, type of sport or physical activity. Further investigations should be conducted to determine the stretching practices and culture in depth in specific sports.

\section{Conclusions}

From the present survey, we concluded that stretching practices were partly in agreement with the literature, for example while considering the modality used for performance. In contrast and in disagreement with the recent literature, most individuals indicated they perform stretching for recovery reasons. Education, instructions, and supervision should be developed to favor appropriate stretching intensity, technique, and positioning. Indeed, from the present survey, supervision appeared poorly provided. Elite competitive individuals appeared more supervised and conducted slightly more adequate and evidence-based stretching sessions. Other gender differences were noticed that could be attributed to the practiced sport and subjective flexibility.

Supplementary Materials: The following is available online at https:/ / www.mdpi.com/article/10 .3390/ijerph18083928/s1, Table S1: Questionnaire used during the present study. Table S2: Effect sizes from Chi-square analyses (Cramer's V).

Author Contributions: N.B., M.C. participated in the study design. N.B. performed the data analysis, interpretation of the results, statistical analyses and produced the first draft of the present manuscript. All authors contributed to data collection and to the manuscript revisions. All authors have read and agreed to the published version of the manuscript.

Funding: This research received no external funding.

Institutional Review Board Statement: The procedure was approved by the ethical review board of the Sports Sciences Faculty in Dijon and was performed in accordance with the Declaration of Helsinki.

Informed Consent Statement: Informed consent was obtained from all subjects involved in the study.

Data Availability Statement: The authors declare that the dataset is available on request.

Conflicts of Interest: The authors declare no conflict of interest.

\section{References}

1. Trall, R. The Illustrated Family Gymnasium; Wells, F., Ed.; Fowler and Wells, Publishers: New York, NY, USA, 1857.

2. Baker, F. Rheumatoid arthritis. Present-day physical therapy. Calif. Med. 1960, 92, 330-333. [PubMed]

3. Kraus, H. Reconditioning aging muscles. Geriatrics 1978, 33, 93-96.

4. Opplert, J.; Paizis, C.; Papitsa, A.; Blazevich, A.J.; Cometti, C.; Babault, N. Static stretch and dynamic muscle activity induce acute similar increase in corticospinal excitability. PLOS ONE 2020, 15, e0230388. [CrossRef]

5. Chaabene, H.; Behm, D.G.; Negra, Y.; Granacher, U. Acute Effects of Static Stretching on Muscle Strength and Power: An Attempt to Clarify Previous Caveats. Front. Physiol. 2019, 10, 1468. [CrossRef] [PubMed]

6. Andrade, R.J.; Freitas, S.R.; Hug, F.; Le Sant, G.; Lacourpaille, L.; Gross, R.; Quillard, J.B.; McNair, P.J.; Nordez, A. Chronic effects of muscle and nerve-directed stretching on tissue mechanics. J. Appl. Physiol. 2020, 129, 1011-1023. [CrossRef] [PubMed]

7. Riccetti, M.; Opplert, J.; Durigan, J.L.Q.; Cometti, C.; Babault, N. Acute Static Stretching Results in Muscle-Specific Alterations amongst the Hamstring Muscles. Sports 2020, 8, 119. [CrossRef] [PubMed]

8. Holt, L.E.; Travis, T.M.; Okita, T. Comparative study of three stretching techniques. Percept. Mot. Skills 1970, 31, 611-616. [CrossRef] [PubMed]

9. McHugh, M.P.; Cosgrave, C.H. To stretch or not to stretch: The role of stretching in injury prevention and performance. Scand. J. Med. Sci. Sports 2010, 20, 169-181. [CrossRef]

10. Behm, D.G.; Blazevich, A.J.; Kay, A.D.; McHugh, M. Acute effects of muscle stretching on physical performance, range of motion, and injury incidence in healthy active individuals: A systematic review. Appl. Physiol. Nutr. Metab. 2016, 41, 1-11. [CrossRef]

11. Kay, A.D.; Blazevich, A.J. Effect of acute static stretch on maximal muscle performance: A systematic review. Med. Sci. Sports Exerc. 2012, 44, 154-164. [CrossRef]

12. Pooley, S.; Spendiff, O.; Allen, M.; Moir, H.J. Static stretching does not enhance recovery in elite youth soccer players. BMJ Open Sport Exerc. Med. 2017, 3, e000202. [CrossRef] [PubMed]

13. Witvrouw, E.; Mahieu, N.; Danneels, L.; McNair, P. Stretching and injury prevention: An obscure relationship. Sports Med. 2004, 34, 443-449. [CrossRef]

14. Sady, S.P.; Wortman, M.; Blanke, D. Flexibility training: Ballistic, static or proprioceptive neuromuscular facilitation? Arch. Phys. Med. Rehabil. 1982, 63, 261-263. [PubMed] 
15. Lucas, R.C.; Koslow, R. Comparative study of static, dynamic, and proprioceptive neuromuscular facilitation stretching techniques on flexibility. Percept. Mot. Skills 1984, 58, 615-618. [CrossRef] [PubMed]

16. Bandy, W.D.; Irion, J.M.; Briggler, M. The Effect of Static Stretch and Dynamic Range of Motion Training on the Flexibility of the Hamstring Muscles. J. Orthop. Sports Phys. Ther. 1998, 27, 295-300. [CrossRef] [PubMed]

17. Wallin, D.; Ekblom, B.; Grahn, R.; Nordenborg, T. Improvement of muscle flexibility. A comparison between two techniques. Am. J. Sports Med. 1985, 13, 263-268. [CrossRef]

18. Moore, M.A.; Hutton, R.S. Electromyographic investigation of muscle stretching techniques. Med. Sci. Sports Exerc. 1980, 12, 322-329. [CrossRef] [PubMed]

19. Wiemann, K.; Hahn, K. Influences of strength, stretching and circulatory exercises on flexibility parameters of the human hamstrings. Int. J. Sports Med. 1997, 18, 340-346. [CrossRef] [PubMed]

20. Ikeda, N.; Yonezu, T.; Kawakami, Y. Minute oscillation stretching: A novel modality for reducing musculo-tendinous stiffness and maintaining muscle strength. Scand. J. Med. Sci. Sports 2020, 31, 104-114. [CrossRef] [PubMed]

21. Ekstrand, J.; Gillquist, J.; Liljedahl, S.O. Prevention of soccer injuries: Supervision by doctor and physiotherapist. Am. J. Sports Med. 1983, 11, 116-120. [CrossRef] [PubMed]

22. Ingraham, S.J. The role of flexibility in injury prevention and athletic performance: Have we stretched the truth? Minn. Med. 2003, 86, 58-61.

23. Woods, K.; Bishop, P.; Jones, E. Warm-Up and Stretching in the Prevention of Muscular Injury. Sports Med. 2007, 37, 1089-1099. [CrossRef] [PubMed]

24. Shellock, F.G.; Prentice, W.E. Warming-up and stretching for improved physical performance and prevention of sports-related injuries. Sports Med. 1985, 2, 267-278. [CrossRef] [PubMed]

25. Cheung, K.; Hume, P.; Maxwell, L. Delayed onset muscle soreness: Treatment strategies and performance factors. Sports Med. 2003, 33, 145-164. [CrossRef]

26. Pooley, S.; Spendiff, O.; Allen, M.; Moir, H.J. Comparative efficacy of active recovery and cold water immersion as post-match recovery interventions in elite youth soccer. J. Sports Sci. 2020, 38, 1423-1431. [CrossRef] [PubMed]

27. Dawson, B.; Gow, S.; Modra, S.; Bishop, D.; Stewart, C. Effects of immediate post-game recovery procedures on muscle soreness, power and flexibility levels over the next $48 \mathrm{~h}$. J. Sci. Med. Sport 2005, 8, 210-221. [CrossRef]

28. Handel, M.; Horstmann, T.; Dickhuth, H.H.; Gülch, R.W. Effects of contract-relax stretching training on muscle performance in athletes. Eur. J. Appl. Physiol. Occup. Physiol. 1997, 76, 400-408. [CrossRef]

29. Kokkonen, J.; Nelson, A.G.; Eldredge, C.; Winchester, J.B. Chronic static stretching improves exercise performance. Med. Sci. Sports Exerc. 2007, 39, 1825-1831. [CrossRef]

30. Behm, D.G.; Chaouachi, A. A review of the acute effects of static and dynamic stretching on performance. Eur. J. Appl. Physiol. 2011, 111, 2633-2651. [CrossRef]

31. Behm, D.G.; Kay, A.D.; Trajano, G.S.; Blazevich, A.J. Mechanisms underlying performance impairments following prolonged static stretching without a comprehensive warm-up. Eur. J. Appl. Physiol. 2021, 121, 67-94. [CrossRef]

32. Avela, J.; Kyrolainen, H.; Komi, P.V. Altered reflex sensitivity after repeated and prolonged passive muscle stretching. J. Appl. Physiol. 1999, 86, 1283-1291. [CrossRef] [PubMed]

33. Winchester, J.B.; Nelson, A.G.; Kokkonen, J. A single 30-s stretch is sufficient to inhibit maximal voluntary strength. Res. Q. Exerc. Sport 2009, 80, 257-261. [CrossRef] [PubMed]

34. Opplert, J.; Genty, J.-B.; Babault, N. Do Stretch Durations Affect Muscle Mechanical and Neurophysiological Properties? Int. J. Sports Med. 2016, 37, 673-679. [CrossRef]

35. Opplert, J.; Babault, N. Acute Effects of Dynamic Stretching on Muscle Flexibility and Performance: An Analysis of the Current Literature. Sports Med. 2018, 48, 299-325. [CrossRef]

36. Samson, M.; Button, D.C.; Chaouachi, A.; Behm, D.G. Effects of dynamic and static stretching within general and activity specific warm-up protocols. J. Sports Sci. Med. 2012, 11, 279-285.

37. Reid, J.C.; Greene, R.; Young, J.D.; Hodgson, D.D.; Blazevich, A.J.; Behm, D.G. The effects of different durations of static stretching within a comprehensive warm-up on voluntary and evoked contractile properties. Eur. J. Appl. Physiol. 2018, 118, 1427-1445. [CrossRef]

38. Judge, L.W.; Petersen, J.C.; Bellar, D.M.; Craig, B.W.; Wanless, E.A.; Benner, M.; Simon, L.S. An examination of preactivity and postactivity stretching practices of crosscountry and track and field distance coaches. J. Strength Cond. Res. 2013, 27, 2456-2464. [CrossRef]

39. Popp, J.K.; Bellar, D.M.; Hoover, D.L.; Craig, B.W.; Leitzelar, B.N.; Wanless, E.A.; Judge, L.W. Pre- and Post-Activity Stretching Practices of Collegiate Athletic Trainers in the United States. J. Strength Cond. Res. 2017, 31, 2347-2354. [CrossRef] [PubMed]

40. Judge, L.W.; Avedesian, J.M.; Bellar, D.M.; Hoover, D.L.; Craig, B.W.; Langley, J.; Nordmann, N.; Schoeff, M.A.; Dickin, C. Pre-and post-activity stretching practices of collegiate soccer coaches in the United State. Int. J. Exerc. Sci. 2020, 13, 260-272. [PubMed]

41. Bouvier, T.; Opplert, J.; Cometti, C.; Babault, N. Acute effects of static stretching on muscle-tendon mechanics of quadriceps and plantar flexor muscles. Eur. J. Appl. Physiol. 2017, 117, 1309-1315. [CrossRef] [PubMed]

42. Opplert, J.; Babault, N. Acute effects of dynamic stretching on mechanical properties result from both muscle-tendon stretching and muscle warm-up. J. Sports Sci. Med. 2019, 18, 351-358. 
43. Freitas, S.R.; Mendes, B.; Le Sant, G.; Andrade, R.J.; Nordez, A.; Milanovic, Z. Can chronic stretching change the muscle-tendon mechanical properties? A review. Scand. J. Med. Sci. Sports 2018, 28, 794-806. [CrossRef]

44. Villanueva, A.; Rabal-Pelay, J.; Berzosa, C.; Gutiérrez, H.; Cimarras-Otal, C.; Lacarcel-Tejero, B.; Bataller-Cervero, A.V. Effect of a long exercise program in the reduction of musculoskeletal discomfort in office workers. Int. J. Environ. Res. Public Health 2020, 17, 9042. [CrossRef]

45. Shariat, A.; Lam, E.T.C.; Kargarfard, M.; Tamrin, S.B.M.; Danaee, M. The application of a feasible exercise training program in the office setting. Work 2017, 56, 421-428. [CrossRef]

46. Holzgreve, F.; Maltry, L.; Hänel, J.; Schmidt, H.; Bader, A.; Frei, M.; Filmann, N.; Groneberg, D.A.; Ohlendorf, D.; van Mark, A. The office work and stretch training (Ost) study: An individualized and standardized approach to improve the quality of life in office workers. Int. J. Environ. Res. Public Health 2020, 17, 4522. [CrossRef] [PubMed]

47. MacEdo, A.C.; Trindade, C.S.; Brito, A.P.; Dantas, M.S. On the effects of a workplace fitness program upon pain perception: A case study encompassing office workers in a portuguese context. J. Occup. Rehabil. 2011, 21, 228-233. [CrossRef] [PubMed]

48. Nuzzo, J.L. The Case for Retiring Flexibility as a Major Component of Physical Fitness. Sports Med. 2020, 50, 853-870. [CrossRef] [PubMed]

49. Bishop, M.D.; George, S.Z. Pain sensitivity and torque used during measurement predicts change in range of motion at the knee. J. Pain Res. 2017, 10, 2711-2716. [CrossRef]

50. Støve, M.P.; Hirata, R.P.; Palsson, T.S. Muscle stretching-The potential role of endogenous pain inhibitory modulation on stretch tolerance. Scand. J. Pain 2019, 19, 415-422. [CrossRef] [PubMed]

51. Apostolopoulos, N.C.; Lahart, I.M.; Plyley, M.J.; Taunton, J.; Nevill, A.M.; Koutedakis, Y.; Wyon, M.; Metsios, G.S. The effects of different passive static stretching intensities on recovery from unaccustomed eccentric exercise-A randomized controlled trial. Appl. Physiol. Nutr. Metab. 2018, 43, 806-815. [CrossRef] [PubMed]

52. Barnett, A. Using recovery modalities between training sessions in elite athletes: Does it help? Sports Med. 2006, 36, 781-796. [CrossRef]

53. Herbert, R.D.; de Noronha, M.; Kamper, S.J. Stretching to prevent or reduce muscle soreness after exercise. Cochrane Database Syst. Rev. 2011. [CrossRef] [PubMed]

54. Miller, K.C.; Harsen, J.D.; Long, B.C. Prophylactic stretching does not reduce cramp susceptibility. Muscle Nerve 2018, 57, 473-477. [CrossRef]

55. Padilha, U.C.; Vieira, A.; Vieira, D.C.L.; De Lima, F.D.; Junior, V.A.R.; Tufano, J.J.; Bottaro, M. Could inter-set stretching increase acute neuromuscular and metabolic responses during resistance exercise? Eur. J. Transl. Myol. 2019, 29, 293-301. [CrossRef] [PubMed]

56. Brunner, R.; Friesenbichler, B.; Casartelli, N.C.; Bizzini, M.; Maffiuletti, N.A.; Niedermann, K. Effectiveness of multicomponent lower extremity injury prevention programmes in team-sport athletes: An umbrella review. Br. J. Sports Med. 2019, 53, 282-288. [CrossRef] [PubMed]

57. Shrier, I. Stretching before exercise does not reduce the risk of local muscle injury: A critical review of the clinical and basic science literature. Clin. J. Sport Med. 1999, 9, 221-227. [CrossRef]

58. Jones, B.H.; Knapik, J.J. Physical training and exercise-related injuries. Surveillance, research and injury prevention in military populations. Sports Med. 1999, 27, 111-125. [CrossRef]

59. Lauersen, J.B.; Bertelsen, D.M.; Andersen, L.B. The effectiveness of exercise interventions to prevent sports injuries: A systematic review and meta-analysis of randomised controlled trials. Br. J. Sports Med. 2014, 48, 871-877. [CrossRef]

60. Babault, N.; Bazine, W.; Deley, G.; Paizis, C.; Lattier, G. Direct relation of acute effects of static stretching on isokinetic torque production with initial flexibility level. Int. J. Sports Physiol. Perform. 2015, 10, 117-119. [CrossRef]

61. Vieira, D.C.L.; Opplert, J.; Babault, N. Acute effects of dynamic stretching on neuromechanical properties: An interaction between stretching, contraction, and movement. Eur. J. Appl. Physiol. 2021, 121, 957-967. [CrossRef]

62. Judge, L.W.; Craig, B.; Baudendistal, S.; Bodey, K.J. An examination of the stretching practices of division I and division III college football programs in the midwestern united states. J. Strength Cond. Res. 2009, 23, 1091-1096. [CrossRef] [PubMed]

63. Lund, H.; Vestergaard-Poulsen, P.; Kanstrup, I.L.; Sejrsen, P. The effect of passive stretching on delayed onset muscle soreness, and other detrimental effects following eccentric exercise. Scand. J. Med. Sci. Sports 1998, 8, 216-221. [CrossRef]

64. Nédélec, M.; McCall, A.; Carling, C.; Legall, F.; Berthoin, S.; Dupont, G. Recovery in soccer: Part II-recovery strategies. Sports Med. 2013, 43, 9-22. [CrossRef] [PubMed]

65. Fowles, J.R.; Sale, D.G.; MacDougall, J.D. Reduced strength after passive stretch of the human plantarflexors. J. Appl. Physiol. 2000, 89, 1179-1188. [CrossRef]

66. Ryan, E.D.; Beck, T.W.; Herda, T.J.; Hull, H.R.; Hartman, M.J.; Stout, J.R.; Cramer, J.T. Do practical durations of stretching alter muscle strength? A dose-response study. Med. Sci Sports Exerc. 2008, 40, 1529-1537. [CrossRef] [PubMed]

67. Torres, E.M.; Kraemer, W.J.; Vingren, J.L.; Volek, J.S.; Hatfield, D.L.; Spiering, B.A.; Ho, J.Y.; Fragala, M.S.; Thomas, G.A.; Anderson, J.M.; et al. Effects of stretching on upper-body muscular performance. J. Strength Cond. Res. 2008, 22, 1279-1285. [CrossRef] [PubMed]

68. Desai, N.; Vance, D.D.; Rosenwasser, M.P.; Ahmad, C.S. Artistic gymnastics injuries; Epidemiology, evaluation, and treatment. J. Am. Acad. Orthop. Surg. 2019, 27, 459-467. [CrossRef] [PubMed]

69. Page, P. Current concepts in muscle stretching for exercise and rehabilitation. Int. J. Sports Phys. Ther. 2012, 7, 109-119. 
70. Nakao, S.; Ikezoe, T.; Nakamura, M.; Saeki, J.; Kato, T.; Umehara, J.; Ichihashi, N. Effects of ankle position during static stretching for the hamstrings on the decrease in passive stiffness. J. Biomech. 2019, 96, 109358. [CrossRef]

71. Iida, N.; Taniguchi, K.; Watanabe, K.; Miyamoto, H.; Taniguchi, T.; Teramoto, A.; Katayose, M. Effective stretching positions for the posterior shoulder capsule as determined by shear wave elastography. J. Shoulder Elb. Surg. 2020. [CrossRef] [PubMed]

72. Apostolopoulos, N.; Metsios, G.S.; Flouris, A.D.; Koutedakis, Y.; Wyon, M.A. The relevance of stretch intensity and position-A systematic review. Front. Psychol. 2015, 6, 1128. [CrossRef] [PubMed]

73. Gentil, P.; Bottaro, M. Influence of supervision ratio on muscle adaptations to resistance training in nontrained subjects. J. Strength Cond. Res. 2010, 24, 639-643. [CrossRef]

74. Coutts, A.J.; Murphy, A.J.; Dascombe, B.J. Effect of direct supervision of a strength coach on measures of muscular strength and power in young rugby league players. J. Strength Cond. Res. 2004, 18, 316-323. [CrossRef] [PubMed]

75. Kofotolis, N.; Kellis, E. Effects of two 4-week proprioceptive neuromuscular facilitation programs on muscle endurance, flexibility, and functional performance in women with chronic low back pain. Phys. Ther. 2006, 86, 1001-1012. [CrossRef] [PubMed]

76. Lempke, L.; Wilkinson, R.; Murray, C.; Stanek, J. The effectiveness of PNF versus static stretching on increasing hip-flexion range of motion. J. Sport Rehabil. 2018, 27, 289-294. [CrossRef] [PubMed] 